\title{
Otomasi Trigger dengan Penentuan Sudut dalam Foto Panorama Berbasis Arduino Uno
}

\author{
Nur Ikhwan Sholihin*1, Danang Lelono ${ }^{2}$ \\ ${ }^{1}$ Program Studi Elektronika dan Instrumentasi, JIKE, FMIPA, UGM, Yogyakarta \\ ${ }^{2}$ Jurusan Ilmu Komputer dan Elektronika, FMIPA UGM, Yogyakarta \\ e-mail: *11nurikhwans@gmail.com, 2danang@ugm.ac.id
}

\begin{abstract}
Abstrak
Dalam pemotretan panorama diperlukan alat bantuyang dapat menentukan besar pergeseran arah kamera secara konsisten agar diperoleh foto-foto yang pas tanpa ada bagian yang hilang karena tidak terfoto. Dengan didapatnya foto yang saling tersambung maka dapat dilakukan penggabungan foto untuk menjadi sebuah foto panorama. Penggabungan foto-foto hasil pemotretan dapat dilakukan dengan cara image stiching (menjahit), yaitu menyambung foto-foto hasil pemotretan dari satu titik tetap.

Alat yang dirancang merupakan alat yang otomatis menentukan besar sudut perputaran head kamera dengan input jumlah pergeseran dan akan melakukan pemotretan (triggering) bila sudut sudah sesuai dengan input. Pengujian sistem meliputi pengujian variasi jumlah pergeseran menggunakan satu nilai focal length dengan memvariasikan nilai pan dan tilt. Pengujian ketelitian konsistensi pergeseran dan arah kamera. Pengujian besar perpotongan setiap pergeseran dengan menggabungkan 2 foto yang sejajar kemudian dicari seberapa besar irisan yang dihasilkan.

Berdasarkan pengujian menggunakan kamera DSLR diperoleh hasil alat dapat bekerja dengan baik secara otomatis berdasarkan nilai input pan dan tilt serta dapat melakukan triggering. Pergeseran efisien diperoleh pada nilai pan sebanyak 9 kali dan tilt 4 kali menggunakan lensa dengan focal length $18 \mathrm{~mm}$. Hasil analisa tingkat kesalahan pergeseran bernilai kurang dari $3 \%$ yang menjadikan alat ini stabil dan konsisten dalam pergerakannya.
\end{abstract}

Kata kunci-foto panorama, Arduino Uno, otomasi, fotografi

\begin{abstract}
In landscape photography, some supporting devices are needed to assign how much the camera's shifting consistently is. It is needed to get good photos without any blank spot photos. The linked photos could be rendered to be a landscape photo using a photography software. It is could be done by image stiching, a way to stich photos taken from one constant taking point.

The device is an automatic device which could assign how much the rotation degree of the camera's head with given input, how much the shift is. It will take a shot if the rotation degree is appropriate with the given input. The system testing by variying the shift value of camera using one focal length value. The accuration test of the consistency of camera's shift and camera's direction. The error value could be determined by joining two parallel photo.

According to the testing, tool can work automatically and also trigering can do well. Efficient shift in the number of photos and good results using the pan 9 times and tilt 4 times. The results of the error rates shift analysis have value less than 3\% and that makes the tool quite stable and consistent in its movements.
\end{abstract}

Keywords - panoramic photo, arduino uno, automation, photography. 


\section{PENDAHULUAN}

$\mathrm{F}$ otografi dengan objek panorama tetap abadi dan tak akan pernah kehilangan penggemar karena alam merupakan hal yang paling eksotis untuk dijadikan karya seni. Fotografi panorama juga bisa diterjemahkan sebagai Landscape Fotografi. Banyak orang mengartikan bahwa landscape fotografi adalah pemandangan alam yang diambil dari jarak jauh sehingga hasil foto adalah gambar alam yang luas. Seperti foto pemandang gunung atau pemandangan laut.

Pada kenyataan yang ada sekarang, proses pembuatan foto panorama masih dilakukan secara manual, baik dengan bantuan tripod maupun tidak. Pemotretan secara manual perlu memutar kamera di tangan atau pada sumbu tripod dan berusaha sestabil mungkin. Namun, jika jarak ke objek terlalu dekat maka bisa terjadi perbedaan paralaks yang akan menyulitkan penggabungan. Kesalahan yang sering terjadi adalah paralaks dan hilangnya suatu sudut atau bagian dari objek. Dalam hal ini maka diperlukan aksesoris tripod khusus yag disebut panoramic head.

Selain itu dalam pemotretan panorama diperlukan alat bantu yang dapat menentukan besar pergeseran arah kamera secara konsisten agar diperoleh foto-foto yang pas tanpa ada bagian yang hilang karena tidak terfoto atau foto yang saling berpotongan secara berlebihan. Dengan didapatnya foto yang saling tersambung maka dapat dilakukan penggabungan foto untuk menjadi sebuah foto panorama. Penggabungan foto-foto hasil pemotretan dapat dilakukan dengan cara image stiching (menjahit), yaitu menyambung foto-foto yang dipotret secara vertikal maupun horisontal dari satu titik tetap.

Pengaplikasian teknologi untuk membantu fotografer tidak bisa dikatakan secara menyeluruh, karena pada prakteknya campur tangan fotografer untuk melakukan pengaturan pada kamera masih sangat diperlukan untuk dapat memperoleh hasil seperti yang diinginkan. Pengaplikasian teknologi pada fotografi hanya sebatas mempermudah cara pemotretan tidak berarti hasil yang diperoleh pasti bagus [1].

Penggunakan optokopler yang berfungsi sebagai isolator juga dapat digunakan sebagai pengontrol trigger pada kamera DSLR yang memang tidak membutuhkan tegangan tambahan dari luar sistem kamera. Dengan menggunakan PC 817 sebagai isolator maka sistem pada kamera akan terpisah dengan sistem pada rangkaian elektronik dengan ATMEGA 8 sebagai pemroses [2].

Implementasi sistem foto panorama untuk mendukung pengoperasian pesawat udara sayap tetap dalam melakukan misi pemantauan, dengan tujuan memudahkan pengguna dalam memantau suatu wilayah dengan teknologi nirkabel. Sistem foto panorama pada purwarupa untuk pesawat tanpa awak ini didukung oleh unit pengiriman yang terdiri dari webcam, modul Raspberry Pi, wireless USB dongle dan motor servo [3].

\section{METODE PENELITIAN}

\subsection{Foto Panorama}

Fotografi panorama adalah kategori foto yang objeknya adalah lingkungan sekitar. Jadi objek dari foto panorama ini adalah alam dan bukan manusia, jikapun ada manusia itu bukan merupakan objek utama dari foto panorama ini. Karena pada dasarnya, objek utama dari fotografi panorama ini adalah seluruh bagian foto, walaupun tetap ada objek yang menjadi pusat dari keindahan foto panorama itu sendiri. Secara umum, foto panorama ini dibuat untuk menunjukkan keindahan dari alam sekitar kita, bahkan dalam sebuah tempat yang hancur kita bisa menunjukkan keindahan dari tempat itu. Diharapkan dengan foto panorama, orang-orang bisa lebih menghargai apa yang ada di alam ini, baik itu alami maupun buatan manusia [4]. 
Google memiliki "Street View" dan Google Maps yang menjadi penerapan panorama. Lukisan panorama yang dulu sangat populer di abad 19, kini bisa dengan mudah dibuat dengan bantuan software. Dalam dunia industri real estate, hotel maupun PC game, semuanya bergantung pada panorama buatan untuk membantu mempresentasikan produk mereka. Versi panorama analog memang masih bisa ditemukan saat ini, misalnya di sector pariwisata, dimana bisa dilihat informasi pada setiap titik didalam foto pegunungan yang luas Secara manual untuk membuat foto panorama dibutuhkan posisi yang statis untuk dapat menghasilkan foto yang saling terkait. Nodal point atau juga pusat titik perputaran arah kamera berada pada ujung lensa. Dengan posisi yang statis dan nodal point yang tepat, maka akan mengurangi efek paralaks [5].

Dengan teknologi yang ada saat ini, dengan mudah kita dapat menyaksikan keindahan panorama sebuah tempat di belahan dunia lain tanpa harus berada langsung di sana. Tidak seperti foto panorama konvensional dengan sudut pandang terbatas, foto panorama $360^{\circ}$ yang telah diproyeksikan ke dalam bentuk virtual menyajikan sudut pandang lebih luas. Pengamat dapat merasakan pengalaman unik dengan melihat ke segala arah, kiri-kanan, atas dan bawah [6].

Macam proyeksi foto panorama dapat diilustrasikan seperti terdapat pada Gambar 1

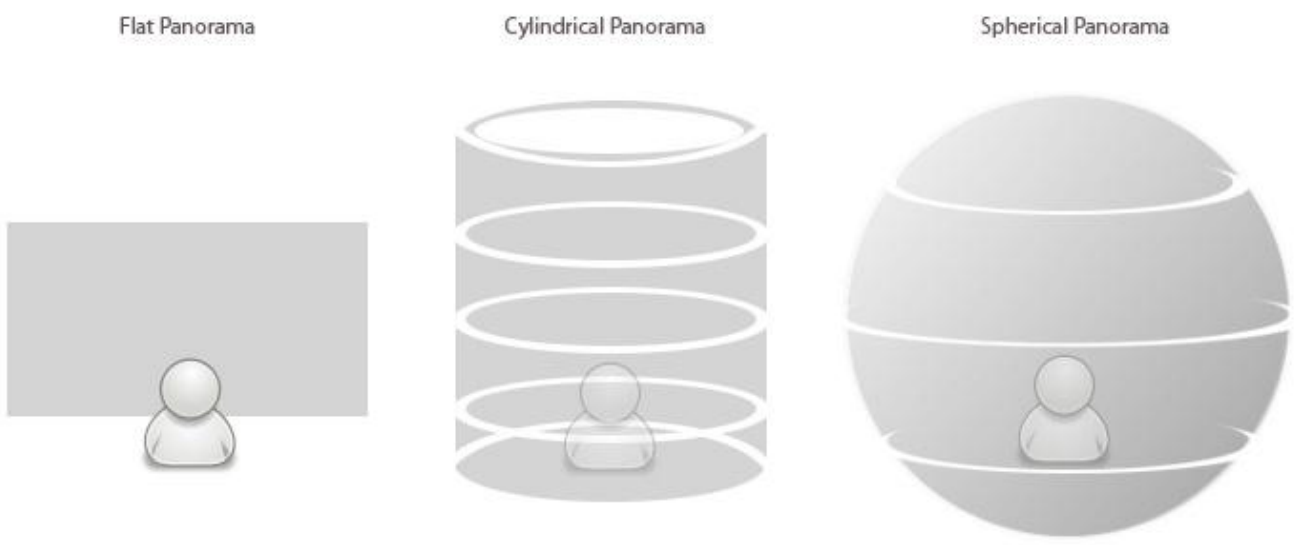

Gambar 1 Ilustrasi macam-macam panorama [6].

Foto panorama dapat dibuat dengan menumpang-tindihkan setiap foto sebesar $20 \%$. Saat pengambilan gambar panorama lakukanlah secara vertikal (orientasi portrait) dengan begitu akan dibutuhkan lebih banyak gambar untuk mencakup area yang sama, tetapi distorsi sudut menjadi berkurang. Menggunakan pelepas rana (shutter release), atau setidaknya self timer agar kamera tidak bergerak saat pemotretan setiap segmen [7].

Secara umum jenis proyeksi foto panorama dapat dibagi dalam tiga bagian, yaitu :

- Panorama datar (flat/plane) yaitu satu foto atau gabungan beberapa foto yang diambil dengan sudut pandang terbatas dan diproyeksikan dalam bentuk datar.

- Panorama Silinder (cylindrical) yaitu gabungan beberapa foto yang diambil berputar $360^{\circ}$ dari kiri ke kanan atau sebaliknya dan diproyeksikan dalam bentuk silinder.

- Panorama Bola (spherical) yaitu foto yang diambil tidak hanya berputar $360^{\circ}$ dari kiri ke kanan tapi juga $180^{\circ}$ ke atas dan bawah. Diproyeksikan dalam bentuk sebuah bola, kita sebagai pengamat berada di dalamnya.

\subsection{Analisis dan Perancangan Sistem}

Sistem yang akan dirancang untuk penelitian ini merupakan suatu alat yang dapat otomatis menentukan besar sudut perputaran head kamera dengan input yang diberikan berupa 
jumlah pergeseran dan kemudian akan melakukan pemotretan (triggering)bila sudut sudah sesuai dengan input. Blok diagram secara keseluruhan ditunjukkan pada Gambar 2.

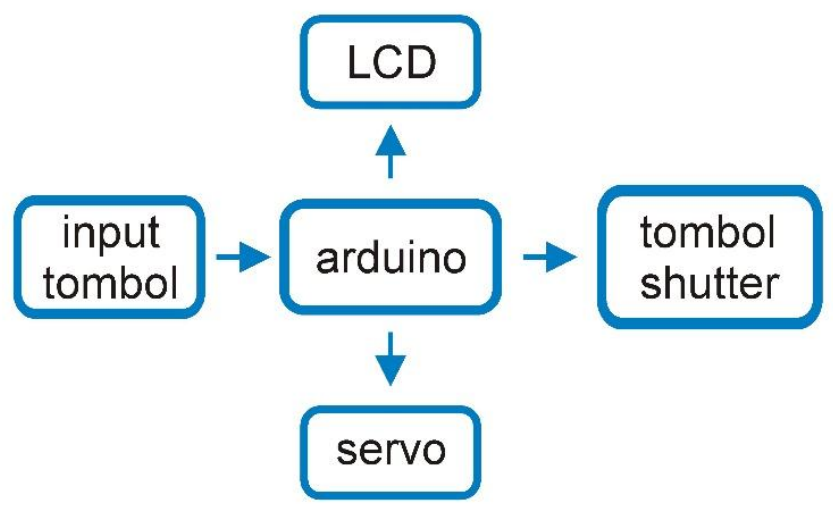

Gambar 2 Blok diagram alat keseluruhan

Prinsip kerja alat ini adalah panorama head akan memutar arah kamera secara vertikal dan horisontal dengan jumlah perputaran sesuai input yang dimasukkan. Nilai input dimasukkan melalui push button yang tersedia dimana nilainya akan menetukan besar sudut perputaran baik horisontal maupun vertikal. Setelah selesai memasukkan nilai masukan dan tombol start ditekan, maka pada titik awal panorama head akan melakukan pemotretan (triggering) kemudian berlanjut secara otomatis pada arah vertikal yang berbeda (tilting) sebanyak masukkan yang telah diberikan, mulai dari titik zenit (titik yang berada diatas kamera) hingga titik nadir (titik yang berada dibawah kamera). Bila sudah terpenuhi pemotretan secara vertikal maka panorama head akan berputar horisontal searah jarum jam sebanyak satu kali, dimana besar sudut pergeserannya telah ditentukan berdasar pada input awal tadi.

Proses pemotretan kembali dilakukan ketika posisi sudut secara horisontal sudah terpenuhi,kemudian berlanjut dengan pemotretan secara vertikal dengan arah kebalikan dari yang pertama atau mulai dari titik nadir (titik yang berada dibawah kamera) hingga mendekati titik zenit (titik yang berada diatas kamera). Jika pemotretan pada arah vertikal telah selesai maka dilanjutkan dengan pemotretan pada arah horisontal. Proses ini akan terus berlanjut dimana arah pergerakan head bergerak secara bergantian antara vertikal dengan horisontal.

Perangkat keras pada alat ini terdiri dari beberapa bagian utama, yaitu bagian penampil antar muka yang akan menampilkan menu antar muka, juga sebagai sarana untuk input nilai jumlah pergeseran. Bagian trigger yang berfungsi untuk melakukan proses penekanan pemotretan secara otomatis ketika head sudah berada pada posisi yang tepat. Bagian controller yang merupakan rangkaian pemroses nilai jumlah pergeseran yang akan dikonversi menjadi nilai besar sudut dan mengatur gerak servo secara bergantian, juga terhubung dengan optokopler sebagai bagian dari trigger. Bagian terakhir adalah bagian servo yang terangkai dengan head yang dapat berputar secara vertikal dan horisontal pada posisi yang statis, dimana bagian servo dan head merupakan aktuator pada sistem ini.

Pengendalian utama pada sistem ini adalah pengendalian secara otomatis arah kamera secara vertikal dan horisontal, dan melakukan pemotretan otomatis ketika posisi arah kamera sudah pada sudut yang sesuai dengan input yang diberikan setelah dikonversi. Program dimulai dengan insialisasi variabel-variabel yang digunakan, kemudian pengguna dapat memasukkan input pan (p) dan tilt $(\mathrm{t})$ yang selanjutnya diolah oleh Arduino sehingga nilai $\mathrm{p}$ menjadi nilai $\mathrm{v}$ dan nilai $t$ menjadi nilai $h$. Hal ini dilakukan sebagai pemisah antara variabel yang digunakan oleh LCD dan yang digunakan oleh motor servo.

\subsection{Implementasi Sistem}

Implementasi perangkat keras pada sistem ini terbagi atas implementasi kerangka dudukan kamera, implementasi kombinasi roda gigi, implementasi kabel trigger, implementasi 
power regulator, implementasi kontroler dengan LCD dan push button. Implementasi pemasangan seluruh komponen perangkat keras pada kerangka dudukan kamera dan kemudian dipasangkan ke tripod seperti ditunjukkan pada Gambar 3.

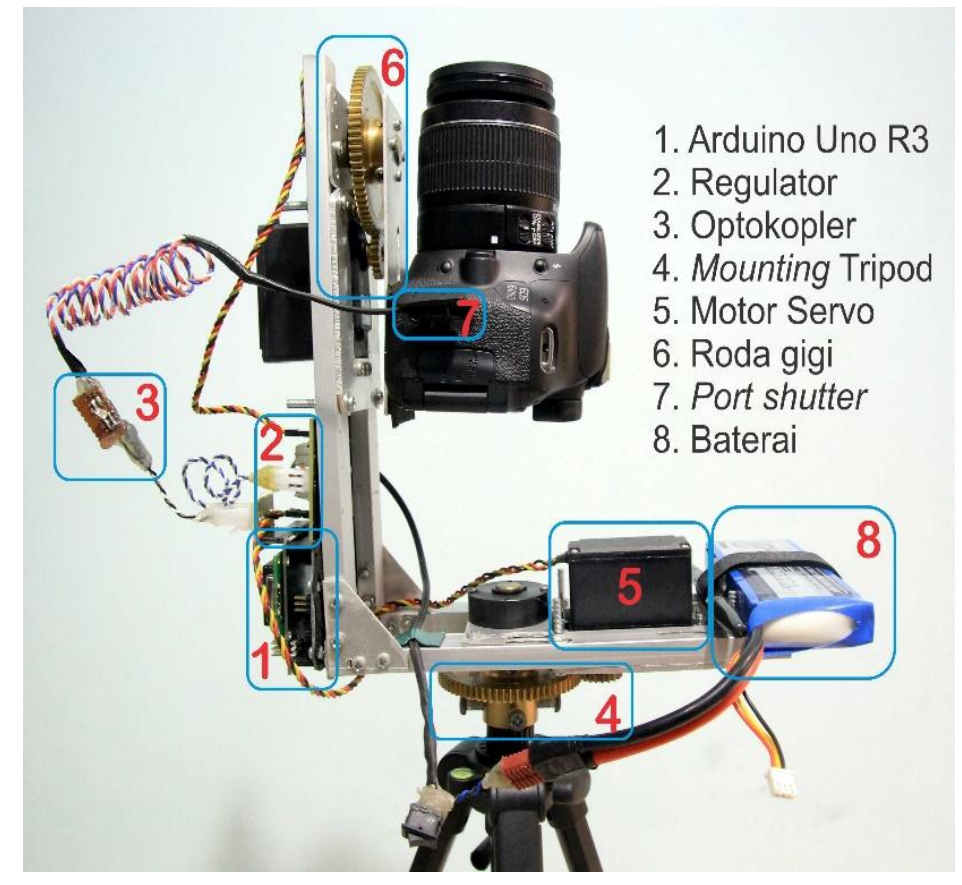

Gambar 3 Perangkat keras sistem secara keseluruhan

Bagian ini akan membahas implementasi perangkat lunak (software) yang digunakan di dalam sistem yang disusun. Implementasi perangkat lunak menggunakan program Arduino IDE 1.0.3 yang meliputi program untuk push button, LCD, kabel trigger dengan fungsi auto trigger, dan motor servo. Arduino Uno R3 yang digunakan sebagai kontroler diprogram menggunakan Arduino IDE 1.0.3 dengan bahasa C. Arduino IDE merupakan perangkat lunak yang beroperasi di komputer dan bertugas untuk menghasilkan sebuah file berformat .hex yang di-upload ke board Arduino Uno. File .hex tersebut dihasilkan dari baris kode yang dinamakan sketch. Sketch yang dibuat Arduino IDE 1.0.3 di-compile dengan perintah 'Verify / Compile' atau Ctrl+R lalu hasilnya di-upload dengan perintah 'Upload' ke Arduino Uno.

\section{HASIL DAN PEMBAHASAN}

\subsection{Pengujian variasi jumlah pergeseran}

Pengujian beberapa variasi jumlah pergeseran dengan memvariasi pergeseran secara horisontal (pan) mulai dari 8 kali pergeseran hingga 10 kali pergeseran dan secara vertikal (tilit) mulai dari 3 kali pergeseran hingga 5 kali pergeseran. Pengujian dilakukan secara outdoor dengan pengaturan pada kamera DSLR menggunakan fokus manual, lebar diafragma f/8, ISO 400, dan focal length $18 \mathrm{~mm}$ yang merupakan focal length terkecil dari lensa standar. Pengujian dilakukan dengan hanya satu nilai focal length dikarenakan mengambil field of view paling luas agar jumlah pengambilan foto semakin sedikit untuk tujuan efisiensi penggunaan memori.

Hasil yang didapat dari pengujian variasi jumlah pergeseran terdapat beberapa foto yang masih belum bisa menjadi satu bagian utuh. Perbandingan hasil berikut dilakukan setelah melalui proses stiching atau penggabungan dengan bantuan perangkat lunak pengolah foto untuk keperluan khusus foto panorama yaitu Autopano Giga. Dari 9 kombinasi antara 
pergeseran horisontal dan vertikal yang kemudian diolah dengan software, didapati 6 hasil yang tidak sempurna dan 3 hasil yang dapat tersambung dengan baik.

Gambar 4 menunjukkan pengujian menggunakan nilai pan sebanyak 8 kali dan tilt sebanyak 3 kali, didapat hasil yang tidak tersambung dengan baik dikarenakan masih ada bagian yang terlewatkan atau tidak terfoto. Secara tilt juga menunjukkan perpotongan antar foto masih kasar sehingga tidak dapat disambung dengan baik.

Gambar 5 adalah hasil pengujian menggunakan nilai pan sebanyak 9 kali dan tilt sebanyak 4 kali, menunjukkan hasil penggabungan foto sudah hampir $100 \%$ tersambung dengan baik, hanya ada satu kesalahan kecil yang belum teratasi yaitu adanya efek paralaks pada bagian atas tiang bendera yang menyebabkan tiang bendera tidak tersambung dengan lurus.

Gambar 6 adalah hasil pengujian menggunakan nilai pan sebanyak 10 kali kemudian nilai tilt sebanyak $5 \mathrm{kali}$, didapat hasil bahwa gambar sudah dapat tersambung dengan baik. Hal itu terbukti dengan tidak adanya bagian foto yang hilang dan efek paralaks yang terjadi.

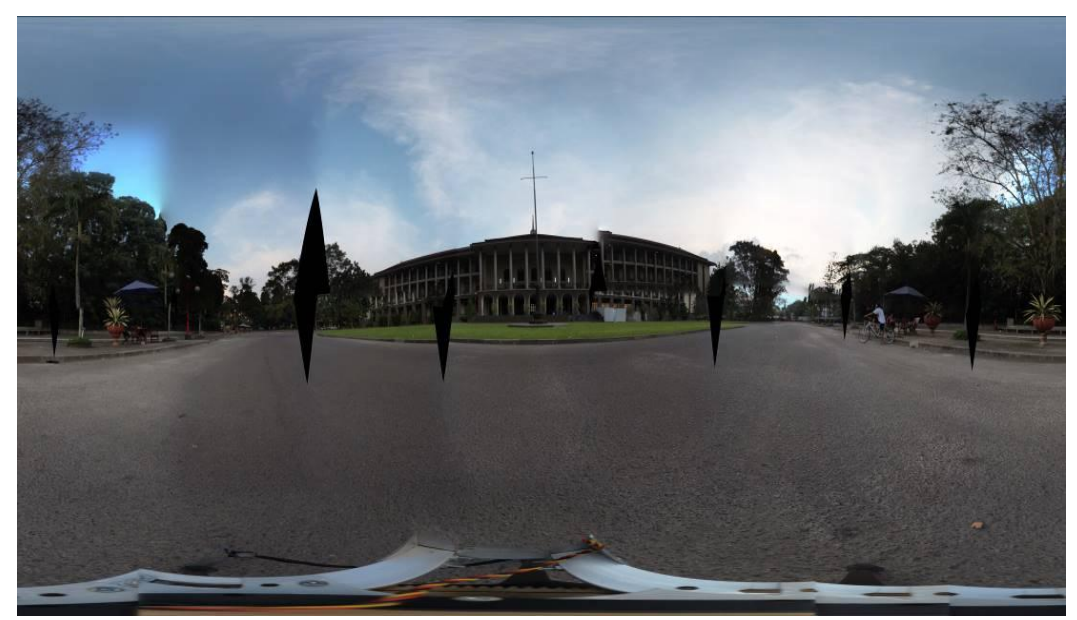

Gambar 4 Foto panorama dengan nilai pan 8 dan tilt 3

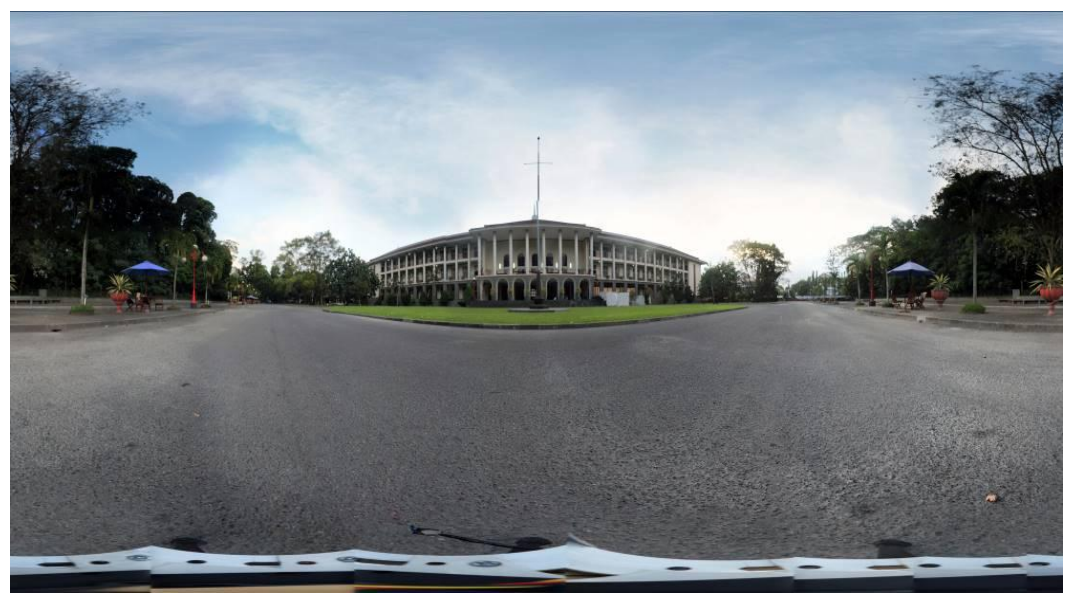

Gambar 1 Foto panorama dengan nilai pan 9 dan tilt 4 


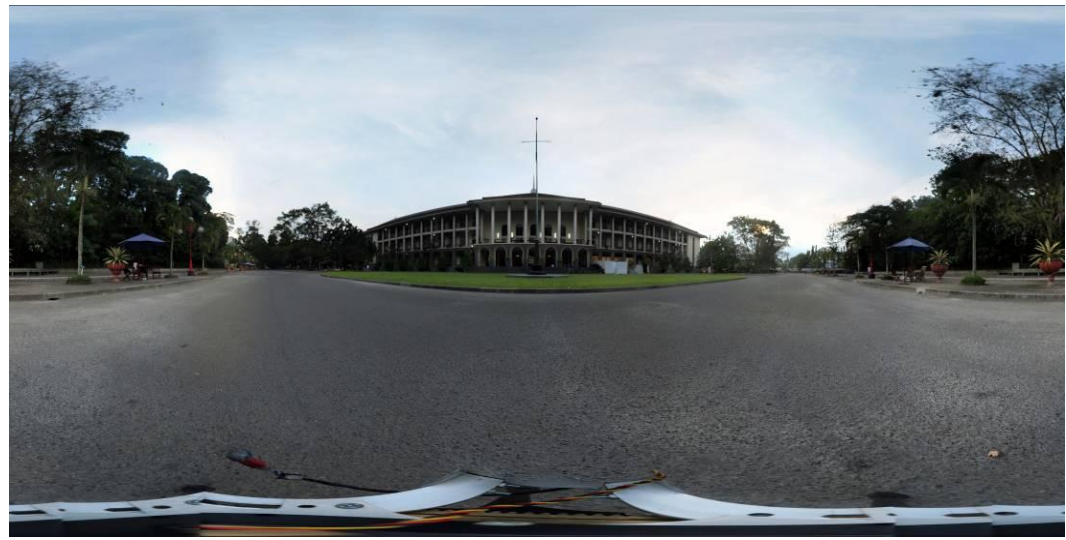

Gambar 0 Foto panorama dengan nilai pan 10 dan tilt 5

Hasil pengujian diperoleh nilai optimal pan 9 kali dan tilt 4 kali dengan kondisi pengujian dilakukan pada lingkup outdoor dan dengan jarak antara kamera dengan objek lebih dari 5 meter. Apabila jarak objek kurang dari 5 meter, maka nilai optimal akan sedikit berubah yaitu nilai pergeseran akan dibutuhkan lebih banyak lagi atau di atas pan 9 dan tilt 4 . Nilai itu dibuktikan ketika melakukan pengujian alat di dalam ruangan dengan jarak antara kamera dengan objek dibawah 3 meter nilai pan 10 dan tilt 5 sudah didapati hasil yang tersambung dengan cukup baik.

Tabel 1 menunjukkan hasil variasi pergeseran tersambung dengan baik atau tidak. Hasil pengujian ditunjukan pada Gambar 4 sampai dengan 6 berurutan mulai dari pergeseran horisontal 8 kali, 9 kali, dan 10 kali dengan kombinasi pergeseran vertikal 3 kali, 4 kali, dan 5 kali.

Tabel 1Hasil pengujian variasi jumlah pergeseran

\begin{tabular}{|c|c|c|c|}
\hline Pan & 3 kali & 4 kali & 5 kali \\
\hline 8 kali & $\begin{array}{c}\text { Tidak tersambung } \\
\text { dengan baik }\end{array}$ & $\begin{array}{c}\text { Tidak tersambung } \\
\text { dengan baik }\end{array}$ & $\begin{array}{c}\text { Tidak tersambung } \\
\text { dengan baik }\end{array}$ \\
\hline 9 kali & $\begin{array}{c}\text { Tidak tersambung } \\
\text { dengan baik }\end{array}$ & $\begin{array}{c}\text { Tidak tersambung } \\
\text { dengan baik }\end{array}$ & $\begin{array}{c}\text { Tersambung dengan } \\
\text { baik }\end{array}$ \\
\hline 10 kali & $\begin{array}{c}\text { Tidak tersambung } \\
\text { dengan baik }\end{array}$ & $\begin{array}{c}\text { Tersambung dengan } \\
\text { baik }\end{array}$ & $\begin{array}{c}\text { Tersambung dengan } \\
\text { baik }\end{array}$ \\
\hline
\end{tabular}

\subsection{Pengujian konsistensi pergeseran dan arah kamera}

Pengujian ini dilakukan dengan pergeseran pan dan tilt secara terpisah, untuk pergeseran secara horisontal digunakan pergeseran sebanyak 8 kali, 9 kali, dan 10 kali dimana masing-masing pergeseran dilakukan berulang dengan membalik arah pemotretan tetapi dengan objek yang sama. Begitu juga dengan pengujian untuk pergeseran vertikal, dilakukan dengan jumlah pergeseran 3 kali, 4 kali, dan 6 kali, juga dengan metode yang sama seperti pada pengujian horisontal. 
Dari hasil pengujian didapati hasil besar nilai kesalahan yang terjadi pada setiap pergeseran yang bervariasi. Berikut nilai besar kesalahan yang terjadi ditampilkan pada Tabel 2 .

Tabel 2 Besar nilai kesalahan setiap pergeseran

\begin{tabular}{|l|c|c|}
\hline \multicolumn{1}{|c|}{ Tipe Pergeseran } & $\begin{array}{c}\text { Besar Nilai Kesalahan } \\
\text { (pixel) }\end{array}$ & Besar Nilai Kesalahan (\%) \\
\hline Pan 8 & 81 & 0,84 \\
\hline Pan 9 & 10 & 0,1 \\
\hline Pan 10 & $<5$ & $<0,05$ \\
\hline Tilt 3 & 275 dan 35 & 2,86 dan 0,24 \\
\hline Tilt 4 & 15 dan 20 & 0,16 dan 0,14 \\
\hline Tilt 5 & 35 dan 20 & 0,36 dan 0,14 \\
\hline
\end{tabular}

Berdasarkan nilai kesalahan yang didapat, besar kesalahan pergeseran tidak mencapai $3 \%$ dari posisi yang seharusnya. Hal ini berarti bahwa pergeseran arah kamera yang terjadi masih bisa ditoleransi karena cakupannya yang tidak signifikan berpengaruh pada hasil pemotretan. Nilai pergeseran yang paling baik berdasarkan tingkat kesalahannya, dengan kata lain paling sedikit nilai error-nyauntuk kondisi pan adalah diatas 10 kali pergeseran.

\subsection{Pengujian besar perpotongan setiap nilai pergeseran}

Pengujian besar perpotongan setiap nilai pergeseran ini bertujuan untuk mengetahui besar nilai perpotongan antar satu foto dengan foto yang sejajar berikutnya pada setiap besar nilai pergeseran. Pengujian dilakukan pada nilai pergeseran pan $8 \mathrm{kali}, 9 \mathrm{kali}$, dan 10 kali.Gambar 7 sampai dengan 9 merupakan ilustrasi besar perpotongan setiap pergeseran.

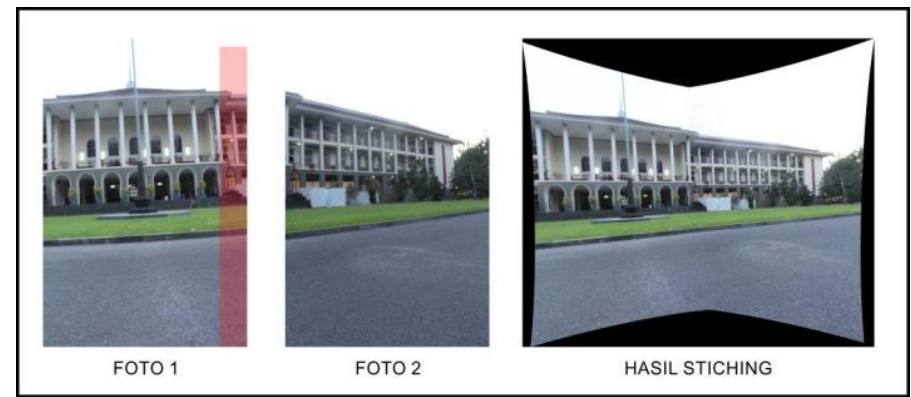

Gambar 7 Besar perpotongan pada pergeseran pan 8 kali

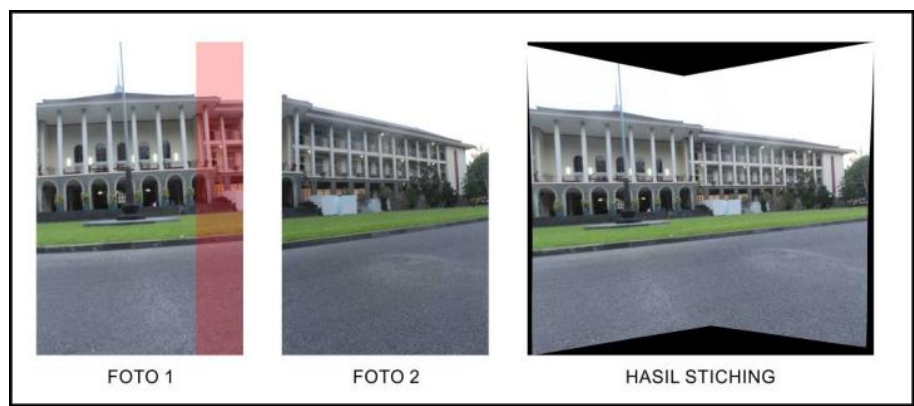

Gambar 8 Besar perpotongan pada pergeseran pan 9 kali 


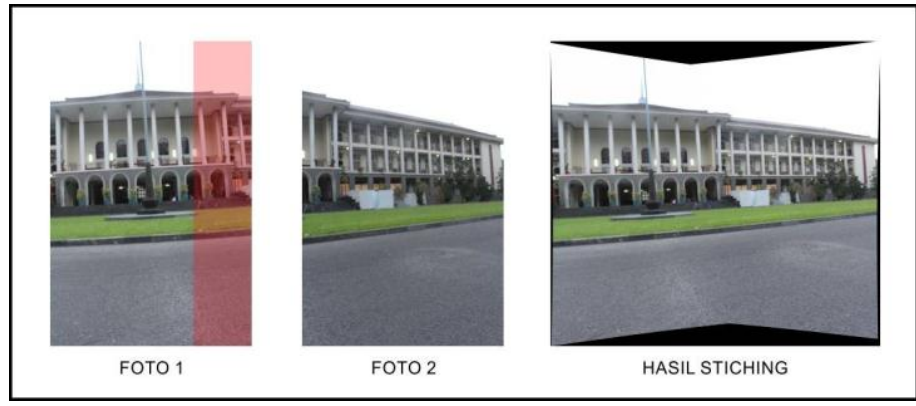

Gambar 9 Besar perpotongan pada pergeseran pan 10 kali

Besar field of view dengan menggunakan focal length lensa $18 \mathrm{~mm}$ pada kamera full frame secara horisontal sebesar $64^{\circ} 30^{\prime}$ kemudian secara vertikal sebesar $45^{\circ} 30^{\prime}$. Dengan menggunakan orientasi secara portrait maka nilai menjadi bertukar antara horisontal dengan vertikal. Ketika dilakukan perhitungan dengan nilai pan 8 kali yang mempunyai besar pergeseran $45^{\circ}$ perpotongan yang terjadi sebesar $30^{\prime}$ atau $0,5^{\circ}$.

Berdasarkan perhitungan tadi dan dikonversi menjadi pixel maka besar perpotongan yang seharusnya dengan pergeseran pan 8 kali adalah 106 pixel atau $1 \%$ bagian yang berpotongan. Namun dalam hasil percobaan perpotongan didapati sebesar 13,6\%. Kemudian untuk nilai pan 9 dan 10 kali dengan besar pergeseran $40^{\circ}$ dan $36^{\circ}$ menghasilkan nilai pergeseran sebesar 1155 pixel dan 1995 pixel atau sama dengan $12 \%$ dan 20,8\%.

Dari 3 pengujian pada pergeseran pan 8, 9 dan 10 kali diperoleh nilai perpotongan sebesar $13,5 \%, 22,75 \%$, dan 28,91\%. Kemudian dari perhitungan berdasarkan spesifikasi lensa dengan focal length $18 \mathrm{~mm}$ diperoleh nilai perpotongan secara berturut-turut untuk nilai pan 8 , 9 dan 10 kali sebesar $1 \%, 12 \%$, dan 20,8\%. Hasil yang diperoleh seperti pada ditampilkan pada Tabel 3.

Tabel 3 Tabel nilai perpotongan

\begin{tabular}{|c|c|c|c|}
\hline Pan & $\begin{array}{c}\text { Nilai perpotongan dari } \\
\text { pengujian }\end{array}$ & $\begin{array}{c}\text { Nilai perpotongan dari } \\
\text { perhitungan }\end{array}$ & $\begin{array}{c}\text { Selisih nilai } \\
\text { perpotongan }\end{array}$ \\
\hline 8 & $13,5 \%$ & $1 \%$ & $12,5 \%$ \\
\hline 9 & $22,75 \%$ & $12 \%$ & $10,75 \%$ \\
\hline 10 & $28,91 \%$ & $20,8 \%$ & $8,11 \%$ \\
\hline \multicolumn{2}{|r|}{ Rata-rata selisih nilai perpotongan } & $10,5 \%$ \\
\hline
\end{tabular}

Didapati adanya selisih pergeseran antara hasil pengujian dibandingkan dengan hasil perhitungan. Rata-rata selisih pergeseran sebesar 10,5\% atau setara dengan 1008 pixel. Besar selisih nilai perpotongan antara hasil perhitungan dan percobaan yang hampir konstan dapat disebabkan karena desain alat yang kurang panjang pada dudukan kamera maupun tripod yang menyebabkan nodal point atau titik pusat perputaran tidak pas ditengah terhadap titik ujung lensa kamera. Selain itu juga dapat disebabkan oleh perputaran servo yang kurang tepat.

\section{KESIMPULAN}

Kesimpulan yang dapat diambil dari penelitian ini adalah sebagai berikut:

1. Alat dapat bekerja dengan baik secara otomatis berdasarkan nilai input pan dan tilt serta dapat melakukan triggering dengan baik.

2. Dengan menggunakan kamera DSLR Canon seri 600D, focal lenth lensa sebesar $18 \mathrm{~mm}$ dan jarak objek lebih dari 5 meter, nilai pergeseran secara horisontal mulai dapat tersambung dengan baik dengan nilai pergeseran sebanyak 9 kali. Sedangkan untuk nilai tilt mulai bisa tersambung dengan baik mulai pergeseran sebanyak 4 kali. 
3. Semakin dekat jarak antara kamera dengan objek, maka nilai pan dan tilt untuk dapat menghasilkan foto panorama yang utuh akan semakin banyak. Begitu juga sebaliknya.

4. Besar nilai kesalahan yang dihasilkan pada setiap pergeseran yang diuji berada kurang dari 3\% dengan pergeseran pan terbaik pada nilai 10 kali pergeseran dan pergeseran tilt terbaik pada nilai 4 kali pergeseran.

5. Terjadi selisih nilai pergeseran antara nilai hasil pengujian dengan nilai hasil perhitungan yang terjadi karena titik pusat perputaran kamera tidak tepat ditengah terhadap ujung lensa.

\section{SARAN}

Pada penelitian ini masih terdapat banyak hal yang harus disempurnakan. Berikut ini disampaikan saran - saran untuk menyempurnakan penelitian dan sistem yang dibuat.

1. Proses stiching hasil pemotretan dari kamera dapat langsung dilakukan pada unit pemroses tanpa bantuan komputer atau laptop.

2. Pengiriman hasil pemotretan dapat dilakukan dari sistem secara wireless ke komputer atau laptop sehingga tidak perlu melepas kartu memori dari kamera yang sangat beresiko kehilangan data apabila tidak hati-hati dalam proses pemindahan.

\section{DAFTAR PUSTAKA}

[1] Noriandita, M, 2009, Sound Trigger High Speed Flash Photography Sensor,Skripsi, Fakultas Matematika dan Ilmu Pengetahuan Alam. Universitas Gadjah Mada, Yogyakarta.

[2] Huwaida, A, 2010, Laser Trigger High Speed Flash Photography Sensor, Skripsi, Fakultas Matematika dan Ilmu Pengetahuan Alam. Universitas Gadjah Mada, Yogyakarta.

[3] Setiyawan, Y, 2013, Purwarupa Sistem Foto Panorama Pada Pesawat Udara Tanpa Awak, Skripsi, Fakultas Matematika dan Ilmu Pengetahuan Alam. Universitas Gadjah Mada, Yogyakarta.

[4] Widyo, B, 2011, Fotografi Landscape (Pemandangan/Panorama), Institut Seni Indonesia Yogyakarta, Yogyakarta.

[5] Andika, M, 2012, Panorama Sempurna, Teknik Panorama, Chip Foto Video 06, Jakarta

[6] Mirtamiharja, C, 2011, Memandang dengan Cara Berbeda di Fotografi Panorama $360^{\circ}$, http://www.indonesiakreatif.net/index.php/id/news/read/mengenal-fotografi-panorama-360, diakses pada 21 September 2012

[7] Kelby, S, 2012, The Digital Photography Book, Volume 1, (diterjemahkan oleh : Nadya Andwiani), Serambi Ilmu Semesta Jakarta. 